\title{
CIÊNCIAS HUMANAS E NEUROCIÊNCIAS Um confronto crítico a partir de um contexto educacional ${ }^{*}$
}

\section{Luiz Fernando Dias Duarte}

Museu Nacional da Universidade Federal do Rio de Janeiro (MN/UFRJ), Rio de Janeiro - RJ, Brasil. E-mail: Ifdduarte@uol.com.br

DOI: $10.1590 / 339702 / 2018$

Para o organismo, a organização é um fato; para a sociedade é o seu a fazer. Canguilhem (1975, p. 333).

\section{O desafio do cerebralismo}

Em dezembro de 2015, foi aberto no Rio de Janeiro o muito aguardado Museu do Amanhá, com uma sede portentosa, desenhada pelo arquiteto Santiago Calatrava e erigida em pleno centro da cidade. A iniciativa fora desencadeada cinco

* Apresentado na mesa-redonda "Natureza e Cultura: expectativas futuras e antigas amarras", 30a Reuniáo Brasileira de Antropologia, João Pessoa (PB), em 5 de agosto de 2016. Agradeço os comentários dos pareceristas anônimos da $R B C S$ para esta versão. anos antes pela Fundação Roberto Marinho e obtivera um crescente apoio da Prefeitura do Rio, no bojo de seu projeto de revitalizaçáo da região portuária da cidade.

Entre as diversas atrações da exposição inaugural, voltada, grosso modo, para a relação entre a tecnociência e a preservação ambiental, surgia todo um módulo intitulado "Pensamento", em que as informaçôes precedentes sobre a natureza cósmica e biológica cediam lugar a uma apresentação da condição humana, o elo essencial em direção ao módulo seguinte, dedicado ao Antropoceno, com a caracterização da devastação antrópica e suas terríveis e previsíveis implicaçóes futuras.

O retrato apresentado buscava mostrar algumas características estruturais e alguns aspectos fenomenais da humanidade, distribuídos entre uma série de dispositivos museográficos nas áreas de circulação e um ambiente mais fechado, um grande cubo, guarnecido de colunas dispostas em labirinto, revestidas de 
imagens variegadas, remissivas a um amplo leque de atividades e instituiçóes humanas.

Para um antropólogo que, como eu, participara como consultor do projeto do museu desde o início de sua concepção, ${ }^{1}$ o que mais chamava a atenção eram dois pontos, diretamente contrários à orientação que procurara imprimir antes a minha contribuição: o cerebralismo radical das referências à condição humana e o caráter aleatório, assistemático e superficial da tentativa de demonstração da variedade e complexidade da experiência sociocultural da humanidade.

Considero necessário procurar compreender esse episódio crítico contemporâneo à luz dos macrodesafios enfrentados pelas ciências humanas em face da ambição reiterada das ciências biomédicas de produzir uma compreensão do humano totalmente "fisicalista" ou "naturalista", o que costuma ser criticamente chamado de "reducionismo" (eventualmente expresso como um "eliminacionismo"). ${ }^{2}$ Recentíssimas reconfiguraçóes das ciências naturais vêm retomando os postulados mecanicistas originais desse campo, refinando-os e reforçando-os (cf. Meloni, 2011, p. 103). O vasto campo contemporâneo das neurociências tem sido pródigo em propostas sobre a preeminência da matéria, ao explorar o funcionamento da conexão cerebral da experiência humana com potentes recursos e ambiçóes de grande envergadura.

A antropologia contemporânea, por outro lado, tem se aberto com grande entusiasmo para uma revisão das bases tradicionais da oposição entre "natureza" e "cultura", seguindo tendências antirrepresentacionalistas e hiperempiristas, que se fundam em um conjunto complexo de argumentos filosóficos e éticos. A ênfase na experiência vivencial e na condição incorporada do pensamento e dos valores tende a produzir um interesse particular na corporalidade e na afetividade, podendo ser eventualmente considerada assim também próxima de uma "naturalização".

Cresce uma robusta literatura sobre as duas tendências, que tem levantado inclusive o tema de uma possível confluência mútua. Essa acumulação crítica exige uma constante revisão dos principais fios do diálogo tenso e desafiador que se vai desenhando entre as posiçóes características dos dois grandes campos, com importantes implicaçóes para o empreendimento antropológico e para o pensamento ocidental em geral, além de exigir uma reflexão sobre as condiçóes e limites da convivência entre esses saberes.

É inesgotável a literatura que trata de ambos os assuntos e é particularmente difícil dar conta do primeiro, o da relação presente entre ciências humanas e neurociências. Não se trata apenas do volume material da produção, mas da intensidade dos debates, polarizados entre o que Fitzgerald e Callard (2014, p. 9) chamam de "retórica da crítica" e de "retórica da exuberância [ebullience]" - a primeira voltada para a denúncia das ambiçóes socioculturais das neurociências (particularmente das "neurociências cognitivas"); a segunda voltada para o enaltecimento do projeto neurocientífico. Nesse sentido, é preciso deixar claro desde já que, embora minha argumentação neste artigo seja bastante típica do registro da "crítica”, ela não se volta evidentemente contra a pesquisa em neurociências em si, mas contra a formulação e uso de ilaçôes socioculturais de seus conhecimentos em contextos gerais de divulgação científica ou formação educativa, aproveitando-se de uma aposta ingênua na maior "cientificidade" de suas propostas e compondo uma estratégia autoritária de desqualificação das ciências humanas.

Como ressalta Alain Ehrenberg (apud Bezerra Júnior, 2007, p. 134):

[...] a última perspectiva [da literatura proponente de um "sujeito cerebral"] é de caráter social e se refere à disseminação de inscriçóes sociais e imaginárias que fazem do cérebro e de suas propriedades biológicas um verdadeiro ator social, e não apenas a condição biológica de possibilidade de existência do self.

Tal concepção do ser humano tem implicações éticas profundas, ao postular um regime de autoridade e responsabilidade mecânico, autorreferido e extrassubjetivo, infenso e hostil à compreensão das condiçóes culturais e psicológicas que instituem os sujeitos na vida social - a única possível para a humanidade.

As críticas das ciências humanas contra as ambições do "programa forte" das neurociências não visam coibir que tais manifestaçóes se deem no 
vasto campo das possibilidades contemporâneas de interpretação da condição humana - o que seria descabido, além de inútil -, mas sim demonstrar como esses desenvolvimentos podem ser incompetentes em sua concepção (à luz de sua outra experiência), temerários em suas promessas apressadas, e autoritários em seu desprezo pelo saber acumulado e corrente das ciências humanas.

A seguir, a segunda seção deste artigo apresenta o material empírico da exposiçáo do Museu do Amanhã, do qual se depreendem diversos aspectos essenciais dos argumentos posteriores. A terceira seção é uma tentativa de oferecer uma ideia geral da multifacetada história do naturalismo ocidental moderno, no que toca o trajeto da invenção do "sistema nervoso" até a conformação do "cerebralismo" contemporâneo. A quarta seção busca fazer um contraponto com as tendências também "naturalizantes" que detecto nos desenvolvimentos recentes da antropologia, partícipes assim de um "estilo de pensamento" (Fleck, [1935] 1979) de grande interesse. Abordo aí também alguns movimentos internos da biologia contemporânea, que permitem tornar mais complexa a atitude da biomedicina em relação ao determinismo. Finalmente, nas conclusóes, trato dos debates disponíveis explicitamente entre os cientistas sociais e as neurociências, para demonstrar suas características e insuficiências, e retorno ao aguilhão local (da exposição do Museu do Amanhã) para amarrar o excurso analítico geral.

\section{Retrato do cérebro enquanto jovem}

Em um texto geral a respeito do módulo "Pensamento", 3 mais ou menos a meia altura do percurso expositivo do Museu do Amanhá, aparece a atribuição ao cérebro humano de causalidade suficiente e linear em relação à experiência sociocultural, como revela o uso do verbo "resultar" na frase seguinte - em que, do "sistema nervoso", coroado pelo cérebro, "resulta" a cultura:

O terceiro cubo, enfim, apresenta a dimensão do Pensamento. No exterior, temos mais uma vez um elemento unificador: nosso sistema nervoso, que é essencialmente o mesmo em todos os seres humanos. Dessa identidade fundamental, no entanto, resulta a incrível diversidade das culturas, ilustrada por centenas de imagens que retratam diferentes aspectos de nossa vida, sentimentos e ações - como habitamos, celebramos, disputamos, pertencemos.

O mesmo uso tendencioso do verbo "resultar" aparece em um texto da bancada interativa, que precede imediatamente o cubo dedicado à cultura:

O cérebro humano - Sensações, emoções, lembranças, movimentos: tudo o que existe para nós resulta de processos realizados pelo cérebro. [...] Está sempre agindo e reagindo [...] (grifo meu).

Toda a complexa evolução da espécie humana, com seus componentes biológicos, corporais, ambientais, culturais, sociais e psicológicos, assim como toda a complexa dinâmica da vida humana histórica, com seus componentes políticos e afetivos, são assim resumidas:

O pensamento se desenvolveu com a evolução da vida. É produzido pelo mais complexo dos órgãos: o cérebro, uma massa de [...] A criatividade humana deu origem à diversidade das culturas, à arte e à ciência.

Teria havido assim uma "evolução da vida" que incluiu o desenvolvimento do pensamento. Mas, como este é produzido pelo cérebro, o que teria havido seria, na verdade, o desenvolvimento do cérebro. Supondo finalmente que a "criatividade humana” seja um efeito do pensamento e, na medida em que este não passa de uma emanação do cérebro, depreende-se que é o cérebro afinal que dá origem à cultura (diversidade, arte e ciência).

A apresentação do cérebro como deus ex machina continua, em outro texto do mesmo equipamento: "Com o desenvolvimento da técnica, o cérebro estende os limites do corpo para além da ponta dos dedos [...]". Ou ainda, e de maneira mais contundente:

Outra grande proeza do cérebro humano foi a aquisição da linguagem [...]. Mas a ciência ain- 
da procura entender como o cérebro de uma criança aprende a representar o mundo por meio da língua.

Por fim, a construção da futura história humana vem a se concentrar nos processos tecnocientíficos de uma ambicionada manipulação do cérebro:

Aprender a identificar padróes de atividade cerebral relacionados a diversos processos pode abrir as portas para explorar o enorme potencial desse órgão. [...].

Todo esse desenvolvimento retórico cerebralista apresenta um fundamento "histórico", filogenético - uma verdadeira cosmogonia -, para a emergência das capacidades do moderno cérebro humano, em hipótese que sugere uma grande mutação natural, arbitrária e aleatória, em direção ao estado de cultura, o que se manifesta em duas diferentes passagens da exposição:

O cérebro além do cérebro - um "excesso" das capacidades existentes no cérebro - quer dizer, a abundância de ligaçóes neuronais que podem ser estimuladas pela aprendizagem - permitiu que os humanos criassem a técnica e a linguagem.

Conhecimento - Tudo começou com um pequeno excesso de células no cérebro. Um excesso que permitiu o desenvolvimento da linguagem e da técnica.

Todas essas informaçôes sobre o cérebro como agente autoinstituído da condição humana precedem o interior do cubo mencionado, onde a "incrível diversidade das culturas" se apresenta sob a forma de um caleidoscópio de imagens coloridas de variadíssima origem, num arranjo despojado de qualquer sistematicidade e necessidade. ${ }^{4}$

A mensagem que decorre da detalhada apresentação do caráter estruturado e estruturante do cérebro contrasta vivamente com a da pitoresca justaposição de uma variedade avulsa e completamente aleatória - que náo deixa de evocar a absurda e imaginária enciclopédia chinesa celebremente citada por Jorge Luis Borges em um de seus contos, e retomada por M. Foucault na abertura de As palavras e as coisas.

\section{O que faz um cérebro?}

O fato de que a experiência humana opera, em certo nível, pela mediação da matéria cerebral dos sujeitos é inquestionável em nossa cultura, pelo menos desde Descartes. O desenvolvimento, nas últimas décadas, das neurociências tem permitido avançar celeremente no conhecimento do funcionamento dessa complexíssima engrenagem, ensejando grandes expectativas quanto às possibilidades técnicas futuras desse saber. Esse papel crucial do órgão começou a ser sistematicamente descrito no século XVII (no contexto do conhecimento sobre o recém-inventado "sistema nervoso" - Duarte, 1986) e nunca deixou de merecer a mais detida atenção pela ciência ocidental moderna, com a construção de diferentes hipóteses e modelos (Figlio, 1975; Vidal, 2005)

O fato de a experiência humana se dar por meio do cérebro não implica, porém, necessariamente pretender que ela tenha origem nesse órgão, ou que seja dele um mero epifenômeno. Muito pelo contrário, tem se discutido amplamente como o surgimento do cérebro "humano" pode ser o resultado de um processo evolucionário, filogenético, em que a materialidade original do cérebro símio interagiu continuamente, por pressões ambientais e acumulação de traços diferenciais, com os primeiros desafios e experiências da cultura e da socialidade humanas, constituindo-se e vindo a sustentar a forma material e as propriedades funcionais do órgão atual.

Clifford Geertz foi o antropólogo a ter mais claramente formulado essa participação da cultura na evolução humana e não apenas em sua história:

[...] não apenas a acumulação cultural já se encontrava em curso bem antes que cessasse o desenvolvimento orgânico, mas [...] essa acumulação muito provavelmente desempenhara um papel ativo na conformação dos estágios finais daquele desenvolvimento (Geertz, 1973, p. 67). ${ }^{5}$ 
Ou ainda:

Entre o padrão cultural, o corpo e o cérebro, criou-se um sistema de retroalimentação positiva, no qual cada um conformava o progresso do outro; um sistema em que a interação entre o crescente uso de ferramentas, a mutante anatomia da mão e a ampliada representação do polegar no córtex é apenas um dos exemplos mais gráficos. Ao se submeter à governança de programas simbolicamente mediados para a produção de artefatos, a organização da vida social ou a expressão das emoções, o homem determinou, mesmo que sem saber, os estágios culminantes de seu destino biológico. Bem literalmente, ainda que inadvertidamente, ele se criou a si mesmo (Geertz, 1973, p. 48).

Mais recentemente, Tim Ingold tem retomado esse ponto, de modo ainda mais eloquente. $\mathrm{Na}$ seguinte passagem, o argumento montado contra o determinismo genético é perfeitamente aplicável ao contexto cerebralista:

[...] o DNA nunca existe em si mesmo, exceto quando isolado artificialmente no laboratório. Ele existe dentro de células, que são partes de organismos, eles próprios situados em ambientes mais amplos. E é somente em virtude de sua incorporação na maquinaria viva da célula que as moléculas de DNA têm os efeitos que têm. Sozinhas, elas não produzem cópias de si mesmas nem constroem proteínas, muito menos organismos inteiros [...]. Logo, o DNA não é um agente, mas um reagente, e as reaçóes particulares que ele póe em movimento dependem do contexto total do organismo no qual ele está situado (Ingold, 2000, p. 14).

Do mesmo modo, em cada evolução ontogenética supóe-se que a modelagem cerebral geneticamente herdada interaja com os estímulos e as condições de vida de cada ser individual (o que sói ser chamado de "ambiente"), moldando uma configuração peculiar, singular, nunca terminada, aliás (graças à chamada "plasticidade neuronal" - Lent, 2010). Esse é o motivo pelo qual é temerário que o cérebro (humano) seja apresentado na exposição como um ente autônomo, um agente exclusivo da história, saído pronto da coxa de Júpiter para ocupar o lugar de demiurgo universal da humanidade. Um cérebro que se faz - e faz o mundo.

A posição hegemônica nas ciências humanas contemporâneas a respeito da relação entre natureza e cultura (ou todas as variaçóes da oposição original cartesiana entre res extensa e res cogitans) considera haver algum tipo de "paralelismo psicofísico" entre o suporte corporal da vida humana e a experiência vital em si, integrada a condiçóes intersubjetivas e coletivas que são necessariamente oriundas do ambiente envolvente de cada sujeito humano e, evidentemente, das propriedades de seu "cérebro". ${ }^{6}$ Essa correspondência ou paralelismo sublinha o caráter necessariamente interativo das diversas dimensões $\mathrm{da}$ condição humana, sem atribuir um caráter determinista nem ao "espírito" nem à "matéria". O mesmo caráter interativo se considera reconhecível nas hipóteses disponíveis sobre a emergência da condição humana a partir de algum momento da evoluçáo dos mamíferos superiores. ${ }^{7}$

A literatura que tenta compreender a eclosão e o rápido desenvolvimento das neurociências na cultura ocidental moderna, no último quartel do século XX, arrola diversas circunstâncias que teriam favorecido uma retomada tão vigorosa da ideologia reducionista (Russo e Ponciano, 2002; Bezerra Júnior, 2010), permitindo sua difusão cada vez mais generalizada, no lugar das interpretaçóes de cunho sociológico ou psicológico dos fenômenos humanos, que se tinham paulatinamente imposto no Ocidente contra as interpretações mágicas ou teológicas (a partir do Renascimento, pelo menos).

Fernando Vidal chama a atenção, muito propriamente, para a marca mais ampla, de longa duração, da concepção da encarnação cristã, que forneceu um dos fundamentos centrais da cosmologia ocidental: a da sacralização da "carne", da dimensão terrena do humano (e, por aí, mais adiante, da "matéria" e da "natureza") (Vidal, 2005, p. 41). Essa peculiar característica da cultura cristá sofreu uma torção importante no século XVII, com a generalização de uma concepção relativamente mais desencarnada da noção de pessoa, graças às aceleradas investigações filosóficas e fisiológicas sobre os 
processos da razão (a mente, o entendimento, o juízo etc.) e da experiência sensorial, que culminaram na descrição de um "sistema nervoso" e na formulação do duradouro modelo dualista de Descartes, mediado justamente por um elemento do cérebro, a glândula pineal. ${ }^{8}$ Começava a se impor então o cérebro como lócus privilegiado da humanidade dos sujeitos humanos.

Essa torção de efeitos persistentes fazia parte da grande transformação cultural que redundou no que se veio a chamar de "modernidade". Os portadores de um sistema nervoso exclusivamente físico, integrado e centrado numa sede cerebral, eram também os portadores de novas qualidades coletivas, como a da "individualidade" subjacente à cidadania associada ao "contrato social” (Duarte, 1986, p. 103). Uma total reconfiguração da relação entre o público e o privado vinha a prevalecer, constituindo as bases da "esfera pública" moderna, associada ao liberalismo político e econômico e aos individualismos quantitativo (liberdade e igualdade) e qualitativo (autonomia e singularidade).

Concomitantemente à noçáo de uma pessoa politicamente livre e dotada de um entendimento ideologicamente desimpedido, espraiaram-se as preocupaçóes com uma nova educação (como em J.-J. Rousseau e Pestalozzi) e generalizaram-se os investimentos no autocultivo dos novos indivíduos (como na Bildung romântica).

O projeto tecnocientífico desencadeado no século XVII, coetâneo da grande transformação política da modernidade, vinha, por outro lado, buscar conhecer a experiência humana à luz dos modelos mecânicos que tinham constituído a linha de frente do avanço científico newtoniano. $\mathrm{O}$ assim chamado "mecanicismo", característico das nascentes ciências biomédicas modernas, cedeu paulatinamente lugar a um "organicismo", graças aos aportes da crítica vitalista, mas não perdeu de vista o ideal de uma explicação dos fenômenos humanos, baseada nos pressupostos materialistas, fisicalistas e naturalistas das ciências exatas. $\mathrm{O}$ organicismo forneceu ao antigo desiderato a justificação empírica para uma concepção autorreferida dos sujeitos humanos, como mônada individual, autônoma, assertiva e autopoiética, coerente com a unidade garantida pelo sistema nervoso/cérebro e pela "razão" nele assentada.
Esse foi e continua sendo o caldo de cultura de onde emergiu o projeto contemporâneo de "naturalização" da mente e da vida social que se expressa nas neurociências (Bezerra Júnior, 2010), mas não apenas, já que se pode vê-lo igualmente pujante na genética, na imunologia, na endocrinologia e nas ciências evolucionárias. ${ }^{9}$

As características de reducionismo, internalismo e individualismo, a que alude Bezerra Júnior (2010, p. 146) ao analisar o campo ideológico em que vicejam as neurociências no início do século XXI, podem ser integradas a esta minha breve evocação das longas linhas de força da cosmologia ocidental: o reducionismo é a continuada tentativa de explicar toda a experiência humana pelas propriedades imediatas da matéria de que se constitui o seu corpo; o internalismo é a continuada ênfase na singularidade monádica de cada sujeito, independentemente de suas relações com o mundo envolvente, ${ }^{10}$ e o individualismo é a generalizada atribuição aos sujeitos humanos da capacidade e obrigação de autogestão. ${ }^{11}$

A disposição reducionista ganhou imenso fôlego com a invenção dos poderosos recursos de visualização do funcionamento interno do cérebro (as neuroimagens funcionais) ora disponíveis, que oferecem supostas confirmaçóes palpáveis da "realidade" observada da vida do órgão ${ }^{12}$ e constituem um solo inesgotável para as pesquisas neurocientíficas.

A disposição individualista (na versão que G. Simmel chamou classicamente de "qualitativa") se articula com processos mais amplos de reordenação dos horizontes ideológicos e éticos da pessoa humana, característicos das últimas décadas do século XX, oferecendo, por meio de empreendimentos comerciais de neurotecnologia, de neurofitness e de neuropreservação, recursos de suposto revigoramento das capacidades individuais (enhancement) e habilitação a uma vida de competência e fruição ilimitadas (Vidal, 2005, p. 38). Esses empreendimentos exterioristas são a contrapartida de uma espécie de exculpação funcional no plano interno, já que a responsabilidade por eventuais incompletudes ou falências não pode ser do sujeito, mas sim de seu cérebro (Azize, 2008, p. 19). Não é à toa que alguns autores associam o boom das neurociências à difusão do neoliberalismo tão generalizadamente, 
intensificada no quadro mundial das últimas décadas como reflexo na ordem coletiva de um individualismo instituinte.

É importante reconhecer que o empreendimento neurocientífico não é uniforme e unívoco, apresentando pelo menos duas grandes tendências, descritas por Alain Ehrenberg (2004) como um "programa forte" e um "programa fraco". O "programa fraco" seria o do desenvolvimento de pesquisas concebidas no interior da problemática do funcionamento do cérebro, sem extrapolaçóes interpretativas para a condição humana em sentido amplo. O "programa forte" seria justamente o seu ambicioso oposto, abrangendo inclusive manifestações superficiais, de popularização, como as ocorridas na exposição do Museu do Amanhã.

Esse "programa forte" constitui todo um campo de experiências e especulaçôes que "busca explicar em termos fisicalistas as atividades da vida subjetiva, tanto individual quanto social, com base na percepção de que o cérebro é o órgão da mente e da vida de relação", como resume Bezerra Júnior (2010, p. 146). Para fazê-lo, vem realizando um vasto programa de pesquisas sobre as mais diferentes manifestações da vida humana, como as da sexualidade (Savic e Lindström, 2008), da religião (Beauregard e Paquette, 2006; Kapogiannis et al., 2009; McGraw, 2012; Lent, 2009) ou da educação (Lent, 2010), para citar apenas algumas que pareceriam menos obviamente passíveis de redução naturalista.

O grau em que essas pesquisas se comprometem com uma representação de causalidade linear, no lugar da mera e mais evidente concomitância, entre o funcionamento cerebral e a experiência sensível e afetiva é muito variável e nem sempre claramente enunciado. Há eventuais remissóes a uma multifatorialidade ou pluricausalidade, além de reiteradas cautelas retóricas no tocante à complexidade dos mecanismos e funções estudadas, que envolvem consideráveis e reconhecidas dúvidas e lacunas. Não obstante, evola de toda a produção a palpável e marcante expectativa do reconhecimento de um exclusivo fundamento in re da condição humana.

Para a antropologia, um dos pontos mais instigantes a compreender nesse fenômeno são as teorias da pessoa que estão aí sendo elaboradas e propostas, com ponderáveis repercussóes para as atividades de educação e formação (escolar, profissional, cívica ou ética).

A tradicional representação ocidental de um livre-arbítrio pessoal (de origem cristã) foi severamente desafiada pelas grandes teorias filosóficas, psicológicas e sociológicas emergentes ao longo do século XIX, que trouxeram à baila diferentes modelos da contingência da condição humana. Teorias políticas, como a da luta de classes ou a da evolução social; teorias psicológicas, como a do inconsciente ou a da imitação; teorias sociológicas como a da autoridade da ordem social ou da preeminência das representações e valores culturais; todas procuraram compreender as condiçóes e limites em que se distende a ação humana, em seus contextos históricos e socioculturais. De modo geral, conviveram, por um lado, com a permanência de ideologias mais "liberais" (baseadas no livre-arbítrio individual), e, por outro, com a emergência de ideologias deterministas de origem biomédica, como no caso da teoria da "degeneração", associada aos movimentos eugenistas e à consolidação do racismo biológico que atravessou - com as trágicas consequências conhecidas - toda a primeira metade do século XX.

$\mathrm{O}$ modelo neurocientífico, subjacente às suas muitas variações internas, surgiu como um híbrido peculiar dos modelos anteriores. Ele certamente dá continuidade e aprofunda o modelo biomédico do determinismo fisicalista, mas acoplado a uma inesperada retradução da ideologia do liberalismo, como reforço das representações "individualistas" hegemônicas no Ocidente desde o século XVIII. Como descreve Vidal (2009, p. 7), a brainhood (cerebralidade), como nova concepção da selfhood (individualidade), se caracterizaria como:

[...] a noção de um self "delimitado", "distanciado" e autônomo, que dispóe da autoconsciência como sua única propriedade constitutiva, e se caracteriza por uma reflexividade radical, um autodistanciamento, um senso de interioridade, um ponto de vista de primeira pessoa, e um descompromisso com o corpo e o mundo.

Essa combinação de determinismo biológico com ideologia liberal se opóe frontalmente à tercei- 
ra tradição mencionada, a das condiçóes (ou determinaçóes) socioculturais e psicológicas do fenômeno humano. Como comentam Russo e Ponciano (2002, p. 25):

O trabalho sobre si, proposto por esse novo aconselhamento científico, não envolve um processo reflexivo de autoexame. Trata-se, ao contrário, de uma espécie de "autocultivo" exteriorizado, que se processa no fazer, na experiência de viver, não em uma indagação sobre si. [...] é a própria ideia de uma interioridade propriamente espiritual ou psicológica que é descartada.

O "sujeito cerebral" é monádico e autorreferido, e o mundo envolvente, seja o intersubjetivo, seja o ambiental, só existe enquanto afetos ou representaçóes individuais que flamejam no fluxo bioquímico da matéria de cada cérebro. ${ }^{13}$

Essa característica leva a que muitas pesquisas neurocientíficas possam se apresentar como dotadas de uma considerável e desconcertante ingenuidade no tocante às características socioculturais dos sujeitos selecionados segundo os pressupostos de sua concepção. Um bom exemplo é o da mencionada pesquisa sobre as diferenças entre homossexualidade e heterossexualidade (Savic e Lindström, 2008). Os pesquisadores, ao compararem a atividade cerebral em "homossexuais" e em "heterossexuais", operam como se os sujeitos envolvidos nessas duas condições ou orientações constituíssem duas espécies biologicamente distintas, ou como se se pudesse definir a priori (ou seja, na seleção dos participantes) uma diferença "natural" univocamente definida. Há décadas se acumula um acervo de pesquisas e análises históricas, sociológicas e antropológicas que demonstra de forma inquestionável a enorme variedade de disposiçóes mentais, comportamentos, afetos e identificaçóes envolvendo a atração física, o engajamento sentimental ou a interação sexual entre sujeitos do mesmo gênero ou de gêneros diferentes, de forma virtual ou efetiva, eventual ou permanente, pública ou encoberta, ritual ou profana, juvenil ou adulta etc. Como nada disso é levado em conta na revisão bibliográfica ou no desenho da pesquisa, o resultado produz um incômodo estranhamento nos profissionais de ciências humanas, ao verem mensuraçóes sofisticadíssimas (e certamente muito caras) das contrapartidas cerebrais de comportamentos ou sensaçóes humanas sendo feitas com base em pressupostos ideologicamente enviesados e empiricamente insustentáveis. ${ }^{14} \mathrm{~A}$ pesquisa, provavelmente em decorrência do tipo de sujeitos selecionados como "homossexuais", apresenta, como magro resultado, a constatação de que os homossexuais masculinos operariam como mulheres e que as homossexuais femininas operariam como homens. Idêntica impressão de desconforto causa a maior parte das pesquisas a respeito da experiência mental das religiosidades, um dos fenômenos mais generalizados, complexos e variados da condição humana, grosseiramente reificados ou reduzidos na maior parte dos experimentos.

A impressão que decorre de tais empreendimentos, montados sobre insubsistentes pré-construçôes do objeto empírico, extravasa para o conjunto das análises neurocientíficas de fenômenos vivenciais humanos, como no caso das interpretaçóes sobre o sofrimento e as perturbaçóes mentais. Neste caso, a situação é particularmente inquietante, já que a psiquiatria contemporânea aderiu maciçamente ao projeto neurocientífico, capaz de finalmente lhe prometer os fundamentos biológicos, fisicalistas, por que ela sempre ansiara, desde o começo do século XIX (cf. Ortega, 2009; Ortega e Zorzanelli, 2010), e já que esses diagnósticos têm implicaçóes concretas para o destino dos padecentes. Apesar da importância das análises socioculturais desses fenômenos, tão amplas quanto as que construiu a antropologia a respeito da sexualidade ou da religiosidade, as interpretaçôes sociogênicas têm sido descartadas em prol de um determinismo neurológico. Também as interpretaçôes psicogênicas disponíveis são descartadas ou submetidas a um processo de subordinação à lógica fisicalista, como no caso das muito variadas e complexas hipóteses da psicanálise. O processo como um todo é concomitante com o avanço acelerado da medicamentalização do sofrimento mental (psicofármacos), acompanhado de perto pelos volumosos interesses da indústria farmacêutica (Azize, 2008; Racine e Costa-von-Aesch, 2011, p. 91).

Algumas análises sublinham o fato de que as neurociências atendem a uma demanda imaginária 
que as precedia, ao invés de terem inaugurado uma verdadeira nova via de compreensão do humano. ${ }^{15}$ Outras sublinham o fato de que essa demanda imaginária é preenchida por uma espécie de wishful thinking, mais do que por efetivos avanços científicos de monta:

Um ponto a enfatizar no desenvolvimento das neurociências concerne ao fato de que a aceitação que mereceu não é proporcional a qualquer inovação ou descoberta definitiva feita em seu campo. Assim, o processo de cerebralização da pessoa não é o resultado do progresso científico, de avanços definitivos no conhecimento da estrutura e funcionamento do cérebro ou de grandes descobertas que consistam em uma base de autoridade construída para o cérebro (Ortega e Zorzanelli, 2010, p. 7).

As neurociências interagem intimamente com as teorias fisicalistas da evolução humana (incluindo uma antropologia e uma psicologia evolucionárias); intensamente comprometidas com a demonstração, no plano filogenético, das causalidades advogadas pelas neurociências para as séries ontogenéticas. ${ }^{16} \mathrm{E}$ náo se pode ignorar o fato de que essa trilha reducionista seguida pelas neurociências é compartilhada pela genética e por outros saberes contemporâneos da biomedicina, que competem entre si pela preeminência na definição dos critérios de um determinismo máximo.

\section{Naturalismo no pensamento antropológico}

Há duas dimensóes do pensamento antropológico contemporâneo que se podem abrigar sob o epíteto de "naturalismo". A primeira é a dos investimentos na compreensão de uma série de características ideológicas e institucionais da experiência humana, que enfatizam a atenção à corporalidade e a seus afetos e "propiciaçôes" (as affordances, de Ingold). A segunda é a das análises do modo como certa concepçâo de "natureza", realidade e vida é intrínseca à cosmologia ocidental e, particularmente, às suas versóes contemporâneas (incluindo as neurociências). ${ }^{17}$
A primeira dimensão tem encontrado recentemente sua versão mais prestigiosa nas formulaçóes da chamada "virada ontológica", em que, por oposição à "virada linguística", que caracterizara a grande contribuição do estruturalismo à compreensão da condição humana, se vem sublinhar a preeminência da mediação corporal da experiência humana. Contra o privilégio intelectualista das representaçóes, retomam-se alguns pressupostos da fenomenologia, com sua ênfase característica na dimensão vivida, experienciada, do estar-no-mundo, ${ }^{18}$ ou do empirismo, com seu atomismo e seu desprezo pelas "abstraçóes". Trata-se de uma corrente que tem se voltado para uma intensa discussão conceitual e programática, lastreada na etnografia das sociedades não ocidentais e de contextos sociais minoritários, dominados ou divergentes (Holbraad, Pedersen e Viveiros de Castro, 2014) - embora apresente uma ambição universal.

A dimensão que me interessa prioritariamente é a segunda, nos muitos tópicos em que se pode situar as neurociências como fenômeno característico das sociedades modernas contemporâneas, mesmo que, em muitos casos, o reconhecimento e a descriçáo de um processo empiricamente constatável possa se articular com alguma valoração epistemológica da "biologização", aproximando tais propostas da primeira dimensão referida. Maria Luiza Assad (2016, p. 163) menciona a categoria de "devires biossociais", de Ingold e Pálsson, como um apto resumo de todo esse processo.

A literatura costuma reconhecer como foco de origem a conceituação, por Michel Foucault, de um "biopoder" e de uma "biopolítica", apresentada em um capítulo do primeiro volume de sua História da sexualidade, publicado em 1976 (Foucault, [1976] 2009; ver ainda Rabinow e Rose, 2006 e Rose, 2003). A essa concepção vêm se acrescentando especificaçóes esclarecedoras como as de "biossocialidade", proposta em 1992 por Paul Rabinow (1996); de "individualidade somática", proposta por Nicholas Rose e Carlos Novas em 2005; de "self neuroquímico" (Rose, 2003); "cidadania biológica" (do mesmo Rose); "bioidentidades", proposta por Ortega e Vidal (2007, p. 257), ou "bioascese" (Ortega, 2008b).

Acrescentam-se a esses instrumentos analíti- 
cos diversos outros mais diretamente voltados para a configuração neurocientífica, como o já citado "sujeito cerebral" (Ehrenberg, 2004, 2011), "neuroessencialismo" (Racine e Costa-von-Aesch, 2011, p. 87), "neurocultura" (Bezerra e Ortega, 2006; Vidal, 2005, 2009) ou "cerebralidade" (brainhood, no original; Vidal, 2009). Ortega e Zorzanelli (2010, p. 8) falam ainda de um "processo de somatização da experiência subjetiva" e Vidal (2009, p. 7) fala de um "interiorismo radical". Assad menciona, além de biosocial becomings (Ingold e Pálsson, 2013), noçóes como as de "biologia da história" (Landecker), ou de embedded bodies (Niewöhner), todas aproximáveis de meu foco (Silva e Duarte, 2016, p. 11).

Essa literatura analítica busca localizar o fenômeno social das "neurociências" em um quadro histórico de grande envergadura, que envolve as macrotransformaçóes socioeconômicas decorrentes da globalização e do revigoramento do liberalismo (e do individualismo) após a falência da Uniāo Soviética, assim como da retomada do prestígio da biomedicina, graças à medicamentalização exacerbada dos fenômenos da vida e à generalização da cultura do enhancement, de uma fruiçáo ilimitada do "bem-viver", garantida pelos recursos biotécnicos. ${ }^{19}$

São de importância estratégica nessa possível aproximação sociológica do universo neurocientífico diversas linhas de relativização de uma "natureza" universal, unívoca, uniforme; externa e estanque em relação à cultura, o que certamente coloca em novos termos a oposição entre natureza e cultura.

A primeira é capitaneada por uma série de etnólogos, como Tim Ingold, Viveiros de Castro e Marilyn Strathern, acompanhados por sociólogos como Bruno Latour, considerados como proponentes ou associados da já citada "virada ontológica". Incluem-se aí movimentos que podem ser chamados de "perspectivismo", "novo animismo" ou "multinaturalismo" (Halbmayer, 2012, p. 9), e cujas características principais consistem em uma relativização radical de concepçóes ocidentais tão estruturantes como as de realidade, natureza, biologia e pessoa. Para os fins desta análise, o mais contundente exemplo desse movimento é o da obra de Tim Ingold (1990), por questionar não apenas a noção ocidental de natureza, mas também as próprias concepçóes da biologia corrente (em sua hegemônica síntese neodarwinista), enfatizando as noçóes de processo, relacionalidade e interaçâo com o ambiente, contra a noção de evolução. Como diz Pitrou, em uma resenha do livro de Ingold e Pálsson (2013):

Ao invés de integrar os fenômenos culturais em um esquema evolucionista clássico, a teoria geral de evolução defendida por Ingold enfatiza a porosidade das fronteiras entre humano e não humano, organismo e ambiente, ao se assumir uma visão (eco) sistêmica, a única visão que permite que se afirme legitimamente que "o domínio do social e o biológico são um só" (Pitrou, 2015).

Nesse mesmo livro, Pálsson chama a atenção para os novos desafios colocados pelas descobertas relativas ao microbioma e ao que agora se chama de "teoria endossimbiótica", incluindo a possibilidade de troca de genes entre os partícipes dessas "zonas de interpenetração", que passam a constituir os organismos complexos.

A segunda linha é a que vem propondo a noção de "biologias locais", a partir da sugestão pioneira de Margaret Lock (1993), baseada em suas pesquisas comparativas sobre as concepçóes culturais e as experiências vitais da menopausa. Como diz a autora:

[...] biologias locais se refere ao modo com que processos sociais e biológicos estão inseparavelmente enredados ao longo do tempo, resultando em diferença biológica humana - diferença que pode ou não ser subjetivamente discernível pelos indivíduos (Lock e Nguyen, 2010, p. 90).

$\mathrm{Na}$ útil revisão do conceito feita por Maria Luiza Assad (2016, p. 79):

[...] biologias locais são o resultado de processos em que nem sempre podemos isolar de maneira nítida um lado biológico e um lado social (equivalente aqui a histórico, político ou cultural) - e por isso podem ser pensadas também como indício desse emaranhado.

A terceira é, finalmente, a das reflexões corren- 
tes sobre o desenvolvimento da epigenética e suas implicações para uma reavaliação das ambições deterministas originais da genética (Meloni, 2015; Silva e Duarte, 2016; Assad, 2016). Os avanços recentes da epigenética desafiam a noção de uma herança mecânica pela via dos genes, ao focar nas alteraçôes em sua expressão decorrentes do "ambiente”, ou seja, de todas as circunstâncias que envolvem os sujeitos, interpessoais e situacionais. Essa perspectiva abre novas possibilidades de concepçáo das fronteiras entre a natureza e a cultura, com a intervenção de dimensóes processuais e relacionais antes escamoteadas. É uma perspectiva dinâmica e interativa, que aproxima, de certa forma, a epigenética da neuroplasticidade.

Esses "naturalismos" aqui evocados são imensamente variados, com interesses analíticos e programáticos díspares, não configurando de modo algum uma tendência uniforme e - muito menos hegemônica. O fio comum que os aproxima - e a diversos outros - da biomedicina é o da atenção privilegiada aos fenômenos da "vida" (como ambíguo conceito deslizante entre condição natural e regime de significação), enquanto o fio que os afasta da biomedicina é o da recusa a qualquer modalidade de fundacionismo físico e realista primordial ou de reducionismo unilinear.

\section{Conclusóes}

O modo como o ser humano é apresentado na exposição do Museu do Amanhã faz dele um subproduto de um de seus órgãos, que, portanto, teria de ter emergido preliminar e autonomamente em relação à espécie, ao organismo e à pessoa de que compóe o conjunto. ${ }^{20} \mathrm{~A}$ subordinação da emergência da linguagem a um "pequeno excesso de células" do cérebro é particularmente tendenciosa, ao propor que esse fenômeno essencial da humanidade - indissociável como é da simbolização - tivesse brotado pronto de um cérebro já plenamente humanizado, no nível filogenético, ou que viesse a fazê-lo repetidamente no caso das evoluçóes ontogenéticas.

Para propor tal hipótese, é necessário atribuir à matéria cerebral uma capacidade autogenética externa à condição do Homo sapiens, sem que se possa conce- ber a emergência dessa capacidade senão pelo aleatório surgimento do suposto "excesso" de células nervosas. ${ }^{21} \mathrm{Ou}$ ainda conceber que uma criança privada de relaçôes intersubjetivas, coletivas, pudesse desenvolver o domínio de uma língua natural, supostamente encastoada, toda pronta, em sua cabeça, desde o Pleistoceno (como no caso dos famosos "meninos lobos", táo discutidos a partir do século XVIII).

Não são raras atualmente as iniciativas no sentido de superar a clivagem entre as ciências humanas e as neurociências, oferecendo argumentos para uma aproximação estratégica, de que adviriam frutos em ambas as direçóes. Aparentemente, elas são mais numerosas na área da psicanálise, provavelmente por força da necessária vizinhança com a psiquiatria de cunho neurocientífico. Não se pode, porém, descartar o fato de que a naturalização neurocientífica atende a uma permanente inquietação "naturalista" interna à psicanálise, costumeiramente formulada em memória do "Projeto de uma psicologia científica”, escrito por Freud, na transição entre sua dedicação à neurologia e a invenção da psicanálise. A expectativa expressa por ele de que a vida psicológica acabaria podendo ser analisada em termos naturalistas descritivos apela a todos aqueles que buscam se afastar do mentalismo hegemônico na psicanálise em direção à corporalidade. $\mathrm{O}$ trabalho de Landeira-Fernandez e Cheniaux (2008) é um exemplo de iniciativas brasileiras nessa direção.

Não parece que sejam numerosos os trabalhos desse tipo com origem nas ciências sociais. Os dois únicos a que tive acesso defendem regimes de interlocução das ciências humanas com as neurociências (Fitzgerald e Callard, 2014; Campoy, 2016), na medida em que venha a ser possível construir uma plataforma de cooperação efetiva.

Fitzgerald e Callard propóem uma revisão das atitudes das ciências humanas em relação às neurociências (2014, pp. 2-3), na perspectiva de um engajamento em "emaranhamentos [entanglements] experimentais" (p. 4), que não se submetam aos protocolos correntes de pesquisas "interdisciplinares". Fazem uma revisão abrangente da literatura atinente às relaçóes entre os dois campos disciplinares e buscam se concentrar nas possibilidades heurísticas de uma participação de cientistas sociais no próprio espaço de experimentação característi- 
co das neurociências. Recorrem, para sustentar essa expectativa, à existência de uma "neurociência crítica” (p. 8), a que corresponderia o movimento de aceitação de uma "teoria da afetação" no seio dos estudos culturais (p. 9). Oferecem inclusive alguma informação sobre duas experiências concretas desse trabalho experimental conjunto, que acreditam ser capaz de tornar os avanços neurocientíficos significativos do ponto de vista das ciências sociais.

Leonardo Campoy (2016, p. 249), por sua vez, considera que a influência das neurociências poderia ser útil para uma necessária superação do dualismo entre natureza e cultura, que se reduplicaria tradicionalmente no que opóe o cérebro à mente. Aposta na possibilidade do estabelecimento de

[...] uma relação de complementaridade entre conexóes neuronais e vivências individuais ou, para colocar no vocabulário mais utilizado pelos cognitivistas, entre organismo e ambiente (Campoy, 2016, p. 262).

E manifesta uma compreensível expectativa positiva em relação à adoção da noção de "neuroplasticidade", ao considerar presente nas neurociências o conceito de

[...] um cérebro mutável ao longo do tempo, não só transformado, mas, principalmente, dependente do ambiente cultural. Um corpo humano interpretado como fisiologicamente disposto às relações sociais (Campoy, 2016, p. 273).

São palavras de esperança em uma interlocução que seria, sem dúvida, do máximo interesse e importância, mas de que não há sinais ou garantias efetivas na literatura disponível (e muito menos nas iniciativas de difusão do saber neurocientífico, diretas ou indiretas), o que torna, por ora, bem pouco realista seu programático veredicto final:

Não é mais preciso desmascarar as assimetrias de poder das lógicas internas do ocidente por meio de uma etnografia das neurociências, tampouco o é tomá-la como um espantalho inimigo para promover a importância da cultura (Campoy, 2016, p. 275).
Há todo um desenvolvimento interno às neurociências voltado para uma ação multidisciplinar a respeito dos "atos humanos que envolvem uma pessoa que pensa e sente, conscientemente ou não, sobre si própria, ou sobre os outros, ou sobre grupos sociais mais amplos" (Cacioppo et al., 2006, p. viii), o que deveria provavelmente ensejar algum diálogo com as ciências sociais. Baseia-se em uma retórica de superação do dualismo "nature vs. nurture" (p. x), embora sua "multidisciplinaridade" não inclua as ciências sociais. Essa "neurociência social" (ou "estudos de cognição social") se restringe a tratar das questôes "sociais" pelo prisma das neurociências, de modo intensamente articulado com a psicologia evolucionária. ${ }^{22}$

Não se pode deixar de registrar que se encontram entre os pesquisadores de neurociências autores de textos de avaliação do campo razoavelmente sensíveis - pelo menos no plano dessa retórica geral à possível convivência entre os dois paradigmas, como é o caso, no Brasil, de Roberto Lent (2008). Mas a consciência das pequenas violências perpetradas pelas neurociências contra as ciências humanas em palcos públicos interdisciplinares contemporâneos, como o do Museu do Amanhá, náo me parece permitir uma atitude irênica em relação às ambiçôes estruturais da disciplina, que ultrapassam em muito o que possa haver de eventual abertura e disponibilidade ao diálogo em seus representantes individuais.

Não se trata absolutamente de postular uma "primazia ontológica" (Fitzgerald e Callard, 2014, p. 9) das ciências humanas sobre as ciências da vida no trato dos fenômenos vivenciais, mentais e comportamentais, mas de garantir sua presença legítima em um campo científico geral em que são frequentemente consideradas anômalas, inconsequentes ou incompetentes. É difícil para as ciências naturais reconhecerem como "científicas" disciplinas ou regimes de saber que náo se rejam pelos cânones naturalistas e fisicalistas da ciência experimental. Efetivamente as ciências humanas nasceram da denúncia dessa tradição iluminista, considerada incapaz de dar conta das qualidades peculiares - sistêmicas, processuais e emergentes - da vida social e mental. Elas não se consideram aquém das qualidades heurísticas das ciências naturais, mas além - no tocante à singularidade dos processos próprios do 
humano. E o que se vê colocado em seu lugar, nas diversas tendências reducionistas em curso, apenas vem reforçando o reconhecimento da incompetência das ciências da vida ao passarem da descrição dos mecanismos vitais para a interpretação, a partir deles, da experiência vital socialmente construída.

É fundamental retornar, a esta altura, ao outro detalhe da exposição do Museu do Amanhã a que fiz referência - aparentemente estranho à cerebralização. Trata-se da composição heteróclita de imagens e categorias sociais, contida num cubo visitável, que deveria representar o essencial do módulo "Pensamento". Como disse, a informação aí contida é totalmente assistemática, aleatória e pitoresca, dando a entender que, enquanto o cérebro é a dimensão fundacional, séria, estruturada, da condição humana, a "cultura" não passa de uma escuma multiforme, volátil e desordenada. A mensagem transmitida, em uma instituição voltada para a promoção de consciência ecológica e educação para a sustentabilidade, parece ser a de que a humanidade terá que se organizar para intervir diretamente no cérebro, caso deseje superar os graves desafios ao seu amanhã. Mas há também a mensagem subliminar de que nada se pode esperar das ciências humanas, colocadas a léguas de distância de qualquer uma das problematizaçóes encenadas no $\mathrm{Mu}$ seu. Há, portanto, uma relação necessária entre o reducionismo cerebralista das mensagens preliminares ao cubo do Pensamento e o esvaziamento conceitual da apresentação das informaçóes sobre a sociedade e a cultura, que torna particularmente insidiosa a solução privilegiada pelos curadores.

Em condições como as atuais, em que os ventos do imaginário social e, com eles, os do campo científico sopram contra a legitimidade específica das ciências humanas, cabe a elas, mais do que nunca, debruçar-se sobre as condições em que se constroem as ciências naturais como fenômeno ideológico e social, desde as suas condições de produção mais técnicas e sofisticadas até as manifestaçôes mais banais e popularizantes.

Faz parte dessa responsabilidade demonstrar como as ideologias científicas (inclusive as suas próprias) se apoiam sobre um solo social e como se movem instigadas por pulsões cognitivas e por estímulos sociais em muito estranhos às racionalizaçóes específicas dos projetos de pesquisa. Felizmente, os estudos sociais da ciência são uma área cada vez mais forte das ciências sociais, dando rica continuidade às contribuiçóes de pioneiros como Ludwik Fleck ou Robert Merton. Os estudos de laboratório, colocados na ordem do dia por Bruno Latour, são uma importante via dessa telescopização, mas não a única. $\mathrm{Eu}$, pessoalmente, ainda acho mais instigante uma perspectiva historicizante, que permita reconhecer os enraizamentos de longa duração de projetos científicos que se acreditam emergindo por geração espontânea do ambiente mesmerizante dos centros de pesquisa e dos laboratórios universitários.

Nesse sentido, cabe sublinhar como parece ao mesmo tempo surpreendente e previsível que certo messianismo cristão, que se encontra na raiz do projeto de iluminação pela ciência da cultura ocidental moderna, possa estar tão ativo por trás do tom triunfante com que se apresenta nessa exposição o "cerebralismo". No lugar do Deus Criador, que não teria mais guarida num museu de ciência e tecnologia (e nem mesmo seu substituto, o Design Inteligente...), entroniza-se outra divindade: um Cérebro onisciente, onipotente e onipresente. Que um "criacionismo laico" possa presidir aos espaços de um templo da ciência e da técnica não é das menores ironias que as ciências humanas detectam e descrevem na trama complexa das sociedades.

\section{Notas}

1 Fui convidado a participar do projeto como consultor em meados de 2009, tendo atendido a demandas espasmódicas das sucessivas equipes de organização até a inauguração da exposição. Nesse último momento fui convidado para compor o Conselho Científico do Museu. Na primeira reunião do Conselho, em fevereiro de 2016, apresentei minhas críticas à apresentação do humano cristalizada na exposição, repetindo as ideias que eu havia recorrentemente expresso, inclusive por escrito, durante as discussóes sobre o conteúdo museográfico - e que tinham vindo a ser desprezadas, sem qualquer informação, debate ou justificativa.

2 Stephen J. Gould assim define "reducionismo": "o desejo de explicar fenômenos parcialmente aleatórios, de larga escala e irredutivelmente complexos pelo comportamento determinista das suas menores par- 
tes constitutivas" (Gould, 1981, p. 27). Ver também Bezerra Júnior (2000, p. 167). O "eliminacionismo" ou "eliminativismo", em sua versão dita "materialista", consiste em recusar realidade aos estados da mente que não sejam reconhecíveis como propriedades da matéria cerebral.

3 Como última parte de um tríptico sobre o "Cosmos", que dá início à exposição do Museu: Matéria, Vida e Pensamento.

4 São dez categorias verbais (amamos, pertencemos, criamos, celebramos, disputamos, produzimos, sentimos, lembramos, habitamos, acreditamos) que se desdobram em 27 categorias nominais completamente aleatórias. No projeto que me haviam encomendado em 2014, eu sugeria algo de semelhante, mas como primeiro passo na direção de uma explicitaçấo da "variedade", "complexidade" e "sistematicidade" da experiência humanae não como mensagem autossuficiente.

5 Ver também, no mesmo sentido, mas de uma perspectiva biológica, Dunbar (1998).

6 A categoria "paralelismo psicofísico" designa o modelo proposto por Leibniz para a relação entre o espírito e a matéria, tal como retomado por W. Wundt (Duarte e Venancio, 1995).

7 O próprio Darwin ([1871] 2004b, p. 61 e 116), em A origem do homem e a seleção sexual, reconheceu o ser humano como um "animal social", e considerou que "a civilização reprime a ação da seleção natural".

8 Esse processo respondia à necessidade de reinstituir os fundamentos da condiçáo humana, despojada de suas garantias transcendentais com a suspensão, pelo menos metodológica, da hegemonia das crenças religiosas (Gusdorf, 1972).

9 Russo e Ponciano (2002, p. 351 e 371) chamam de "monismo naturalista" à tendência contemporânea mais geral a que pertencem as neurociências, baseado, nas últimas décadas do século XX, em um antirracionalismo e um antidualismo estruturantes: "a atual tendência à adoção de uma visão totalmente naturalizada do ser humano - sobretudo daquelas características, tais como consciência, razão, linguagem, que tradicionalmente o distinguiam dos outros animais corresponde à ancoragem do espírito no corpo, o que significou não tanto uma redução materialista do humano, mas uma transfiguração espiritual da natureza material. Esta, como se viu, passa a ser dotada de características tradicionalmente vistas como humanas, em uma espécie de neovitalismo sem princípio vital. Parecemos estar frente a uma Lebensphilosophie materialista, fundada em uma crítica ao paradigma racionalista clássico e ao materialismo mecanicista e afirmando a vida como valor supremo".

10 "O individualismo característico das sociedades ocidentais e ocidentalizadas, o valor supremo dado ao indivíduo como agente autônomo da escolha e da iniciativa, e a ênfase correspondente na interioridade às custas dos vínculos e contextos sociais, são sustentados pela ideologia da cerebralidade e reproduzidos pelos discursos neuroculturais" (Vidal, 2009, p. 7).

11 Rogério Azize (2008, p. 14 e 16) contribuiu para a compreensão da disseminaçáo dos valores das neurociências ao associá-los à ideologia contemporânea do enhancement ou self-improvement, generalizada disposição em fazer ampliar as capacidades interativas e comportamentais dos sujeitos mediante recursos de controle e treinamento. A noçáo de "bioascese", trabalhada por Francisco Ortega (2008a), também designa aspectos desse processo.

12 O caráter construído das imagens que se tornam evidências científicas é ressaltado por diversos autores. Fernando Vidal (2009, p. 27) diz, por exemplo, que "as neuroimagens funcionais podem ser ícones modernos, mas [...] resultam de uma cadeia de decisóes sobre o processamento de dados numéricos, e fazem parte das práticas locais de produção, recepçáo e comunicação que se acrescentam à sua complexidade tecnológica. O que isso implica para a materialização das invisíveis qualidades e experiências psicológicas, e para a transformação de processos materiais em imaterialidade?”. Pode-se ver ainda, sobre esse ponto, Ortega e Vidal (2011, p. 13); Ortega e Zorzanelli (2010) e Zorzanelli (2011).

13 As noçóes de neurochemical self (Rose, 2003) e de somatic individuality apontam para a mesma configuração (Carlos Novas e Nicholas Rose, apud Ortega e Vidal, 2007, p. 256).

14 As correntes homólogas de determinismo natural da homossexualidade - endocrinológico e genético -são examinadas respectivamente em Nucci (2010) e em Fry e Carrara (2016).

15 Esse papel de garantia quase mágica de processos associados à "política de identidades" é cumprido tanto pelas neurociências quanto pela genética. No primeiro caso, é interessante mencionar os movimentos sociais subsumidos na categoria "neurodiversidade", em que o argumento do funcionamento cerebral avaliza uma demanda identitária afinada com o espírito do tempo por parte de diversos segmentos antes marcados por algum estigma ou "deficiência”. A “'neurodiversidade' se torna um valor que os 'neurotípicos' devem respeitar” (Ortega e Vidal, 2007, p. 257; Ortega, 2008a). 
16 A clássica crítica de Marshall Sahlins (1976) à sociobiologia demarcou uma posição mais afirmativa da antropologia em relação aos determinismos biológicos reavivados a partir dos anos 1960 (Sahlins, 2008). Para uma boa revisão recente das posições "antinaturalistas", ver Meloni (2011, p. 109).

17 O etnólogo americanista Philippe Descola nomeou como "naturalismo" uma das quatro grandes concepçóes cosmológicas (ou "ontologias") que considera prevalecentes entre as diversas culturas humanas. É a que caracterizaria justamente as sociedades ocidentais (ou euro-americanas) modernas (Descola, 2013); fundada, como é, na crença em uma natureza una, unívoca e já dada exteriormente à experiência humana.

$18 \mathrm{Na}$ verdade, um processo de mais longo curso, radicado na reaçáo romântica ao racionalismo iluminista $\mathrm{e}$ indissociável de toda a evoluçâo das ciências humanas graças ao seu centramento na subjetividade, no fluxo, na pulsão e na experiência. A filosofia de Nietzsche encarnou plenamente os ideais dessa tradição, demarcando um caminho palmilhado pelos empiristas contemporâneos (Duarte, 2004).

19 "A neurociência nada mais faz que seguir e aprofundar o caminho já traçado pela chamada medicina do comportamento (psiquiatria, psicanálise, psicologias), oferecendo um aconselhamento especializado na arte do "bem viver" (Russo e Ponciano, 2002, p. 25). Ver, sobre a ideologia do enhancement, Azize (2008).

20 A chamada "falácia mereológica", nos termos de Bennett e Hacker, comentados por Meloni (2011, p. 110).

21 O princípio darwiniano da seleçáo natural realmente opera a partir de mutaçóes aleatórias, mas elas só se preservam no processo evolutivo quando servem à "luta pela vida", ou seja, contribuem para uma melhor sobrevivência no meio ambiente em que vicejam (Darwin, [1859] 2004a, p. 160-161). Que haja um "excesso de células" aleatoriamente surgido no cérebro não é explicação suficiente para nenhum traço evolutivo; é preciso que essas células sejam postas em ação em determinada direção, que a seleção preservará ou náo. O surgimento da linguagem e da cultura depende, portanto, de alguma outra explicaçáo, menos linear e autógena.

22 A psicologia cognitivista, em geral, e a psicologia evolucionária, em particular, contribuem intensamente para os debates aqui resenhados, eventualmente patrocinando discussões que se pretendem interdisciplinares, como se pode ver, por exemplo, em Whitehouse (2001).

\section{BIBLIOGRAFIA}

ASSAD, Maria Luiza G. (2016), Situando a biologia: de biologias locais à epigenética. Dissertação de mestrado, Rio de Janeiro, Instituto de Medicina Social, Uerj.

AZIZE, Rogério L. (2008), "Uma neuro-weltanschauung? Fisicalismo e subjetividade na divulgação de doenças e medicamentos do cérebro". Mana - Estudos de Antropologia Social, 14 (1): 7-30.

BEAUREGARD, M. \& PAQUETTE, V. (2006), "Neural correlates of a mystical experience in Carmelite nuns". Neurosci Lett, 405 (3): 186-190.

BEZERRA JÚNIOR, Benilton. (2000), "Naturalismo como antirreducionismo: notas sobre cérebro, mente e subjetividade". Cadernos IPUB, VI (18): 158-177.

BEZERRA JÚNIOR, Benilton. (2007), "Da contracultura à sociedade neuroquímica: psiquiatria e sociedade na virada do século", in M. I. M. Almeida e S. C. Naves (orgs.), "Por que não?" Rupturas e continuidades da contracultura, Rio de Janeiro, 7 Letras.

BEZERRA JÚNIOR, Benilton. (2010), "Neurociências e Psicanálise: definindo discordâncias para construir o diálogo". Revista APPOA - Associação Psicanalitica de Porto Alegre, 38: 145-159.

CACIOPPO, J. T. et al. (orgs.). (2006), Social neuroscience: people thinking about thinking people. Cambridge, MA, MIT Press.

CAMPOY, Leonardo C. (2016), "Como o cientista social pode se relacionar com as neurociências contemporâneas. Discurso nativo ou voz analítica?", Sexto Caderno: Novas Antropologias, 5 (6): 238-278.

CANGUILHEM, Georges. (1975), Études d'histoire et de philosophie des sciences. Paris, Vrin.

DARWIN, Charles. ([1859] 2004a), A origem das espécies. São Paulo, Martin Claret.

DARWIN, Charles. ([1871] 2004b), A origem do homem e a seleção sexual. Belo Horizonte, Itatiaia.

DESCOLA, Philippe. (2013), Beyond nature and culture. Chicago, University of Chicago Press.

DUARTE, Luiz F. D. (1986), Da vida nervosa (nas classes trabalhadoras urbanas). Rio de Janeiro, Jorge Zahar. 
DUARTE, Luiz F. D. (2004), "A pulsão romântica e as ciências humanas no Ocidente". Revista Brasileira de Ciências Sociais, 55: 5-18.

DUARTE, Luiz F. D. \& VENANCIO, Ana T. A. (1995), "O espírito e a pulsão (o dilema físico-moral nas teorias da pessoa e da cultura de W. Wundt)". Mana - Estudos de Antropologia Social, 1 (1): 69-98.

DUNBAR, Robin I. M. (1998), "The social brain hypothesis". Evolutionary Anthropology, Issues, News, and Reviews, 6 (5): 178-190.

EHRENBERG, Alain. (2004), "Le sujet cerebral”. Esprit, 309: 130-155.

EHRENBERG, Alain. (2011), "The 'social' brain: an epistemological chimera and a sociological fact", in F. Ortega e F. Vidal (orgs.), Neurocultures: glimpses into an expanding universe, Frankfurt/Nova York, Peter Lang.

FIGLIO, Karl M. (1975), "Theories of perception and the physiology of mind in the late eighteenth century". History of Science, 13: 177-212.

FITZGERALD, D. \& CALLARD, F. (2014), "Social Science and neuroscience beyond interdisciplinarity: experimental entanglements". Theory, Culture \& Society, 32, 1: 3-32.

FLECK, Ludwik. ([1935] 1979), Genesis and development of a scientific fact. Chicago/Londres, The University of Chicago Press.

FOUCAULT, Michel. ([1976] 2009), "Direito de morte e poder sobre a vida", in M. Foucault, História da sexualidade 1: a vontade de saber, Rio de Janeiro, Graal.

FRY, Peter \& CARRARA, Sérgio. (2016), “'Se oriente, rapaz!' Onde ficam os antropólogos em relação a pastores, geneticistas e tantos "outros" na controvérsia sobre as causas da homossexualidade?". Revista de Antropologia, 59 (1): 258-280.

GEERTZ, Clifford. (1973), The interpretation of cultures. Nova York, Basic Books.

GOULD, Stephen J. (1981), The mismeasure of man. Nova York/Londres, W. W. Norton.

GUSDORF, Georges. (1972), Dieu, la nature, l'homme, au siècle des lumières. Paris, Payot.

HALBMAYER, Ernst. (2012), "Debating animism, perspectivism and the construction of ontologies". Indiana, 29: 9-23.
HOLBRAAD, Martin; PEDERSEN, Morten Axel \& VIVEIROS DE CASTRO, Eduardo. (2014), "The politics of ontology: anthropological positions. Theorizing the contemporary", Cultural Anthropology. Disponível em: <https://culanth. org/fieldsights/462-the-politics-of-ontology-anthropological-positions $>$. Acesso em: 4 jan. 2017.

INGOLD, Tim. (1990), "An anthropologist looks at biology". Man, 25 (2): 208-229.

INGOLD, Tim. (2000), “'Gente como a gente’: o conceito de homem anatomicamente moderno". Ponto Urbe: Traduçôes, 9. Disponível em: $<$ https://pontourbe.revues.org/1823>. Acesso em: 4 jan. 2017.

INGOLD, Tim \& PÁLSSON, Gisli (orgs.). (2013), Biosocial becomings: integrating social and biological anthropology. Cambridge, Cambridge University Press.

KAPOGIANNIS, D. et al. (2009), "Cognitive and neural foundations of religious belief". Proceedings of the National Academy of Sciences of the USA. Disponível em: <www.pnas.org/cgi/ doi/10.1073/pnas.0811717106>. Acesso em: 4 jan. 2017.

LANDEIRA-FERNANDEZ, J. \& CHENIAUX, E. (2008), "Discussão de um tratamento psicanalítico sob a ótica das neurociências: a importância de sistemas implícitos e funçóes executivas no processo terapêutico". Revista Universidade Rural, 30 (1): 19-31.

LENT, Roberto. (2008), "A cultura muda o cérebro?”. Ciência Hoje on-line. Disponível em: $<$ http://www.cienciahoje.org.br/noticia/v/ler/ id/4405/n/a_cultura_muda_o_cerebro $>$. Acesso em: 4 jan. 2017.

LENT, Roberto. (2009), "A religiosidade e o cérebro". Ciência Hoje on-line. <http://www.cienciahoje. org.br/noticia/v/ler/id/4397/n/a_religiosidade_e_o_cerebro $>$. Acesso em: 4 jan. 2017.

LENT, Roberto. (2010), "A educação muda o cérebro". Ciência Hoje on-line. Disponível em: <http://www.ciencia.org.br/noticia/v/ler/ id/4384/n/a_educacao_muda_o_cerebro/ Post_page/29>. Acesso em: 4 jan. 2017.

LOCK, Margaret. (1993), Encounters with aging: mythologies of menopause in Japan and North America. Berkeley, University of California Press. 
LOCK, Margaret \& NGUYEN, Vinh-Kim. (2010), An anthropology of biomedicine. Oxford, UK, Wiley-Blackwell.

MCGRAW, John. (2012), "Tongues of men and angels: assessing the neural correlates of glossolalia”, in D. Cave e R. S. Norris (orgs.), Religion and the body: modern science and the construction of religious meaning, Leiden, Brill.

MELONI, Maurizio. (2011), "The cerebral subject at the junction of Naturalism and Antinaturalism", in F. Ortega e F. Vidal (orgs.), Neurocultures: glimpses into an expanding universe, Frankfurt/Nova York, Peter Lang.

MELONI, Maurizio. (2015), "Epigenetics for the social sciences: justice, embodiment, and inheritance in the postgenomic age". New Genetics and Society, 34 (2): 125-151.

NUCCI, Marina F. (2010), Hormônios pré-natais e a ideia de sexo cerebral: uma análise das pesquisas biomédicas sobre gênero e sexualidade. Dissertação de mestrado, Rio de Janeiro, Instituto de Medicina Social, Uerj.

ORTEGA, Francisco. (2008a), "O sujeito cerebral e o movimento da neurodiversidade". ManaEstudos de Antropologia Social, 14: 477-509.

ORTEGA, Francisco. (2008b), O corpo incerto: corporeidade, tecnologias médicas e cultura contemporânea. Rio de Janeiro, Garamond.

ORTEGA, Francisco. (2009), "Deficiência, autismo e neurodiversidade". Ciência \& Saúde Coletiva, 14 (1): 67-77.

ORTEGA, Francisco \& VIDAL, Fernando. (2007), "Mapping the cerebral subject in contemporary culture". RECIIS - Electronics Journal of Communication Information and Innovation in Health, 1 (2): 255-259.

ORTEGA, Francisco \& VIDAL, Fernando. (orgs.) (2011), Neuroculture: glimpses into an expanding universe. Frankfurt/Nova York, Peter Lang.

ORTEGA, Francisco \& ZORZANELLI, Rafaela. (2010), "The cerebralization of fatigue: an analysis of the cerebral hypothesis in the case of chronic fatigue syndrome". História, Ciências, Saúde - Manguinhos, 17, 2. Disponível em: <http://dx.doi.org/10.1590/S010459702010000200002>. Acesso em: 23 nov. 2017.
PITROU, Perig. (2015), "Uma antropologia além de natureza e cultura?". Mana - Estudos de Antropologia Social, 21 (1): 181-194.

RABINOW, Paul. (1996), "Artificiality and enlightenment: from sociobiology to biosociality", in P. Rabinow, Essays on the anthropology of reason, Princeton, Princeton University Press.

RABINOW, Paul \& ROSE, Nicholas. (2006), "O conceito de biopoder hoje". Politica \& Trabalho. Revista de Ciências Sociais, 24: 27-57.

RACINE, Eric \& COSTA-VON-AESCH, Zoë. (2011), "Neuroscience's impact on our self-identity: perspectives from ethics and public understanding", in F. Ortega e F. Vidal (orgs.), Neurocultures: glimpses into an expanding universe, Frankfurt/Nova York, Peter Lang.

ROSE, Nikolas. (2003), "Neurochemical selves". Society, 41, 1: 46-59.

ROSE, Nikolas \& NOVAS, Carlos. (2005), "Biological citizenship”, in A. Ong e S. Collier (orgs.), Global assemblages: technology, politics and ethics as anthropological problems, Malden, MA, Blackwell.

RUSSO, Jane A. (2001), "A pós-psicanálise: entre Prozac e Florais de Bach”, in A. M. Jacó-Vilela, A. C. Cerezzo e H. B. C. Rodrigues (orgs.), Clio-Psyche. Hoje. Fazeres e dizeres psi na história do Brasil, Rio de Janeiro, Relume Dumará.

RUSSO, Jane \& PONCIANO, Edna T. (2002), “O sujeito da neurociência: da naturalização do homem ao reencantamento do mundo". Physis Revista de Saúde Coletiva, 12 (2): 345-373.

SAVIC, Ivanka \& LINDSTRÖM, Per. (2008), "PET and MRI show differences in cerebral asymmetry and functional connectivity between homo- and heterosexual subjects". PNAS, Proceedings of the National Academy of Sciences, Early Edition. Disponível em: <www.pnas.org_cgi_doi_10.1073_ pnas.0801566105>. Acesso em: 4 jan. 2017.

SAHLINS, Marshall. (1976), The use and abuse of biology: an anthropological critique of sociobiology. Ann Arbor, Michigan Press.

SAHLINS, Marshall. (2008), The Western illusion of human nature: with reflections on the long history of hierarchy, equality, and the sublimation of anarchy in the west, and comparative notes on other conceptions of the human condition. Chicago, Prickly Paradigm Press. 
SILVA, Gláucia O. \& DUARTE, Luiz F. D. (2016), "Epigênese e epigenética: as muitas vidas do vitalismo ocidental". Horizontes Antropológicos, 22 (46). Disponível em: <http://dx.doi. org/10.1590/S0104-71832016000200015>. Acesso em: 4 jan. 2017.

VIDAL, Fernando. (2005), "Le sujet cérébral: une esquisse historique et conceptuelle". Psychiatrie, Sciences Humaines, Neurosciences, III (11): 37-48.

VIDAL, Fernando. (2009), "Brainhood, anthropological figure of modernity". History of the Human Sciences, 22 (1): 5-36.

WHITEHOUSE, Harvey. (2001), The debated mind: evolutionary psychology versus ethnography. Londres, Bloomsbury.

ZORZANELLI, Rafaela T. (2011), "Sobre o poder de persuasão das imagens médicas”. RECIIS Revista Eletrônica de Comunicação, Informação e Inovação em Saúde, 5 (2): 44-52. 


\section{CIÊNCIAS HUMANAS E NEUROCIÊNCIAS: UM CONFRONTO CRÍTICO A PARTIR DE UM CONTEXTO EDUCACIONAL}

\section{Luiz Fernando Dias Duarte}

Palavras-chave: Neurociência; Museu; Ciência; Determinismo; Naturalismo.

A antropologia contemporânea tem se aberto com grande entusiasmo para uma revisão das bases tradicionais da oposição entre "natureza" e "cultura", seguindo tendências antirrepresentacionalistas e hiperempiristas que se fundam em um conjunto complexo de argumentos filosóficos e éticos. Ao mesmo tempo, novas configuraçôes das ciências naturais retomam os postulados mecanicistas originais dessa área. $\mathrm{O}$ vasto campo contemporâneo das neurociências tem sido pródigo em propostas materialistas deterministas, ao explorar a conexão cerebral da experiência humana com potentes recursos e ambiçóes de grande envergadura. A coetaneidade desses movimentos sugere que se resuma em que se aproximam e se distinguem esses "naturalismos" biomédicos e antropológicos. Mas se trata aqui sobretudo de resumir os principais fios do diálogo tenso que se vai desenhando entre as posiçóes características dos dois grandes campos, com importantes desafios para o empreendimento antropológico; tal como expresso nas exposiçóes do recente Museu do Amanhá, no Rio de Janeiro.

\section{HUMAN SCIENCES AND NEUROSCIENCES: A CRITICAL CONFRONTATION AS SEEN FROM A BRAZILIAN EDUCATIONAL CONTEXT}

\section{Luiz Fernando Dias Duarte}

Keywords: Neuroscience; Museum; Science; Determinism; Naturalism.

Contemporary anthropology has opened itself with great enthusiasm to a revision of the traditional bases of the opposition between "nature" and "culture", following anti-representationalist and hyperempiricist trends based on a number of philosophical and ethical postulates. At the same time, new configurations in the natural sciences return to their characteristic mechanist models, reasserting their original tenets. The broad contemporaneous field of neurosciences abounds in proposals based on a deterministic materialism, emerging from top technology and broad scope research about the connection between the nervous system and human experience. The coetaneity of these movements demands an expatiation about the points of convergence and divergence between biomedical and anthropological "naturalisms". It is then necessary to gather some of the links of the tense dialogue in process among the sundry positions in both fields, involving eminent challenges for the anthropological endeavor; as expressed especially in the exhibits of the new Museu do Amanha (Museum of Tomorrow), in Rio de Janeiro.

\section{SCIENCES HUMAINES ET NEUROSCIENCES: UNE CONFRONTATION CRITIQUE À PARTIR D'UN CONTEXTE ÉDUCATIF}

\section{Luiz Fernando Dias Duarte}

Mots-clés: Neurosciences; Musée; Science; Déterminisme; Naturalisme.

L'anthropologie contemporaine s'est ouverte avec beaucoup d'enthousiasme à une révision des bases traditionnelles de l'opposition entre la "nature " et la " culture ", suivant les tendances anti-représentationnalistes et hyper-empiristes qui se confondent dans un ensemble complexe d'arguments philosophiques et éthiques. Parallèlement, de nouvelles configurations des sciences naturelles ont repris les postulats mécanicistesoriginaux de ce domaine. Le vaste champ des neurosciences contemporaines a été riche en propositions matérialistes déterministes en explorant la connexion cérébrale de l'expérience humaine avec de puissants moyens et des ambitions à grande échelle. La contemporanéité de ces mouvements suggère que l'on résume en quoi s'approchent et se distinguent les " naturalismes " biomédicaux et anthropologiques. Mais il s'agit principalement de résumer les principaux fils conducteurs du dialogue tendu qui se dessine entre les positions caractéristiques des deux grands domaines, avec des défis importants à l'entreprise anthropologique tel que cela est exprimé dans les expositions récentes du récent Museu do Amanhã (Musée de Demain) à Rio de Janeiro. 


\section{ERRATA}

RBCS vol.33 no 97/2018

DOI: $10.1590 / 339700 / 2018 E R$

E-location: e339700ER

- Nos artigos: "O comitê de articulação federativa no governo Lula: os percalços da cooperação territorial”; "Marcuse crítico de Weber: a política no capitalismo tardio"; "Representação política: a virada construtivista e o paradoxo entre criação e autonomia"; "O pequeno investidor na bolsa brasileira: ascensão e queda de um agente econômico"; "Ciências humanas e neurociências: um confronto crítico a partir de um contexto educacional"; "A peculiaridade do maquiavelismo inglês: das origens ao século XVII"; "Internacionalização de micro, pequenas e médias empresas inovadoras no Brasil: desafios do novo paradigma de desenvolvimento"; "A luta pelo reconhecimento e o paradigma da dádiva: uma proposta de articulação teórica" e "Determinantes individuais e de contexto da simpatia partidária na América Latina”, assim como nas resenhas: "Um acerto de contas com o judiciário argentino", "A imprevisibilidade democrática" e "Idle No More: sobre a mobilização indígena no Canadá", publicados na Revista Brasileira de Ciências Sociais, 2018, volume 33, número 97, cujos e-locations são respectivamente: e339703, e339704, e339705, e339710, e339702, e339706, e339708, e339709, e339711, e339715, e339716 e e339717, os prefixos do DOI estáo incorretos.

Onde se lia: “10.590”

Leia-se: "10.1590". 